\title{
Inocybe myriadophylla, a new species from Finland and Sweden
}

\author{
JUKKA VAURAS and ELLEN LARSSON
}

\begin{abstract}
VAURAS, J. \& LARSSON, E. 2012: Inocybe myriadophylla, a new species from Finland and Sweden. - Karstenia 51: 31-36. Helsinki. ISSN 0453-3402.

Inocybe myriadophylla, a new species of subgenus Mallocybe, is described from NW Europe. It is characterized by crowded lamellae. The species favours calcareous habitats, and seems to be associated with Betula. A description, illustrations, and a phylogenetic tree are presented.
\end{abstract}

Key words: Agaricales, Basidiomycetes, Fennoscandia, Inocybe, Mallocybe, taxonomy

Jukka Vauras, Biological Collections of Abo Akademi University, Herbarium, University of Turku,FI-20014 Turku,Finland; e-mail: jukka.vauras@utu.fi

Ellen Larsson, Department of Plant and Environmental Sciences, University of Gothenburg, P.O. Box 461,SE-40530 Göteborg, Sweden; e-mail: ellen.larsson@dpes.gu.se

\section{Introduction}

The genus Inocybe is one of the largest genera of Agaricales in Europe. In Funga Nordica there are 154 species of Inocybe in the key (Jacobsson 2008), only twelve species of which belong to subgenus Mallocybe. Kühner (1988) reported fifteen taxa of Mallocybe from French Alps, including 11 new ones, which are still not well understood. The characteristics of Mallocybe are the tomentose to scaly pileus, which is not radially fibrillose, the stem which is often shorter than cap diameter, and the often septate cheilocystidia originating from hymenophoral trama (Jacobsson 2008).

With the traditional macroscopical and microscopical methods it has been possible to identify easily only a few species of Mallocybe. The use of ITS sequence data has greatly facilitated the possibilities to sort out and identify species of the subgenus (Cripps et al. 2010). The new species presented here can be identified already in the field by the pale pileus in young fruitbodies and the crowded and narrow lamellae. The phylogenetic analysis based on of ITS and LSU sequence data support I. myriadophylla as a distinct species.

\section{Material and methods}

Macroscopical characteristics were noted and cross sections taken from fresh fruit bodies collected in Finland. Colour codes refer to Cailleux (1981) or Küppers (1981). Microscopical characteristics were studied with a Leitz Laborlux D. The drawings were made with the Leitz drawing tube under an oil-immersion objective to magnification of 2000. All measurements and drawings are based on dried material mounted in $10 \% \mathrm{NH}_{4} \mathrm{OH}$. Twenty mature spores were measured from five paratypes and from two fruit bodies of the holotype $(n=140)$. Values within $5 \%$ of each end of the range of spores are given in parentheses. The $\mathrm{Q}$-value means the ratio of spore length to spore width (calculated for each spore). The basidia lengths were measured excluding the sterigmata. The collections from which the microscopical measurements were taken are marked with an asterisk in the list of examined specimens. The specimens where the collection number is followed by the letter " $F$ " include a photo taken in situ.

Molecular methods. For this study four specimens of the morphologically identified new species were sampled 
Table1. Data of the sequenced specimens

\begin{tabular}{|l|l|l|l|}
\hline Species & Coll. ID. / Origin & Ecology, substrate & $\begin{array}{l}\text { GB No. } \\
\text { ITS/LSU }\end{array}$ \\
\hline Inocybe myriadophylla & JV19652 / Fin & Picea, Betula, Pinus & HM209791 \\
\hline Inocybe myriadophylla & EL121-08 / Swe & Picea, Betula Populus & HM209792 \\
\hline Inocybe myriadophylla & JV19678 / Fin & Picea, Pinus, Populus & HM209793 \\
\hline Inocybe myriadophylla & JV5968 / Fin & Betula, Picea, Pinus & HM209794 \\
\hline Inocybe agardhii & EL88-04 / Swe & Salix, Betula & FJ904123 \\
\hline I. agardhii & AB980912 / Den & Salix & HM209790 \\
\hline I. arthrocystis & EL62-07 / Swe & S. herbacea & FN550941 \\
\hline I. fuscomarginata & EL109-06 / Swe & S. herbacea & FN550940 \\
\hline I. fuscomarginata & BJ890718 / Swe & Salix & GU980656 \\
\hline I. gymnocarpa & EL78-04 / Swe & Picea, Corylus & AM882865 \\
\hline I. gymnocarpa & SJ980707 / Swe & Picea & AM882866 \\
\hline I. leucoblema & SM2324 / Swe & Picea & GU980630 \\
\hline I. leucoblema & JV2898 / Fin & Picea, Betula & HM209789 \\
\hline I. leucoloma & EL40-07 / Swe & S. reticulata & GU980622 \\
\hline I. leucoloma & EL50-05 / Nor & Dryas, S. reticulata & AM882855 \\
\hline I. leucoloma & Ohenoja880810 / Svalbard & Dryas, S. reticulata & HM209786 \\
\hline I. malenconii & SJ030822 / Swe & Pinus & AM882862 \\
\hline I. malenconii & JV23101 / Fin & Betula, Salix, Picea & HM209787 \\
\hline I. malenconii & PAM98041302 / Fra & Betula, Pinus & HM209788 \\
\hline & & & \\
\hline
\end{tabular}

for sequencing. In addition six morphologically fairly similar species from subgenus Mallocybe were included. Inocybe arthrocystis Kühner was selected for rooting of trees based on results from earlier molecular phylogenetic studies (Cripps et al. 2010, Ryberg et al. 2010). Data of the specimens is presented in Table 1. Sequences of the complete ITS region, 1200 base pairs of the 5'end of the nuclear LSU ribosomal DNA were generated. DNA extractions, PCR reactions and sequencing of recently collected specimens were performed as described in Larsson $\&$ Örstadius (2008). Sequences were edited and assembled using Sequencher 3.1 (Gene Codes, Ann Arbor). Sequences were aligned automatically using the software MAFFT (Katoh et al. 2005) and adjusted manually using the data editor in PAUP* (Swofford 2003). Sequences have been deposited in GenBank and accession numbers are listed in Table 1. Heuristic searches for most parsimonious trees were performed using PAUP*. All transformations were considered unordered and equally weighted. Variable regions with ambiguous alignment were excluded and gaps were treated as missing data. Heuristic searches with 1000 random-addition sequence replicates and TBR branch swapping were performed. Relative robustness of clades was assessed by the bootstrap method using 1000 heuristic search replicates with 100 random taxon addition sequence replicate, TBR swapping.

\section{Inocybe myriadophylla Vauras \&}

\author{
E. Larss., sp. nova \\ MycoBank no.: MB 564068 \\ - Figs. 1-3
}

Pileo $1.8-7.5 \mathrm{~cm}$ lato, tomentoso, primum pallido cano-brunneolo, dein pallido brunneo. Lamellis densis et angustis, usque ad $4 \mathrm{~mm}$, raro ad $7 \mathrm{~mm}$ latis, aetate provectis brunneis. Stipite 2.5-5 cm longo, 0.3-0.7 mm crasso, pallido, fibrilloso. Sporis (7.3-)7.9-9.6(-10.6) × (4.5-) 4.7-5.5(-5.7) $\mu \mathrm{m}$, laevibus, plus minus regularibus vel phaseoliformibus. Cheilocystidiis 9-30× 

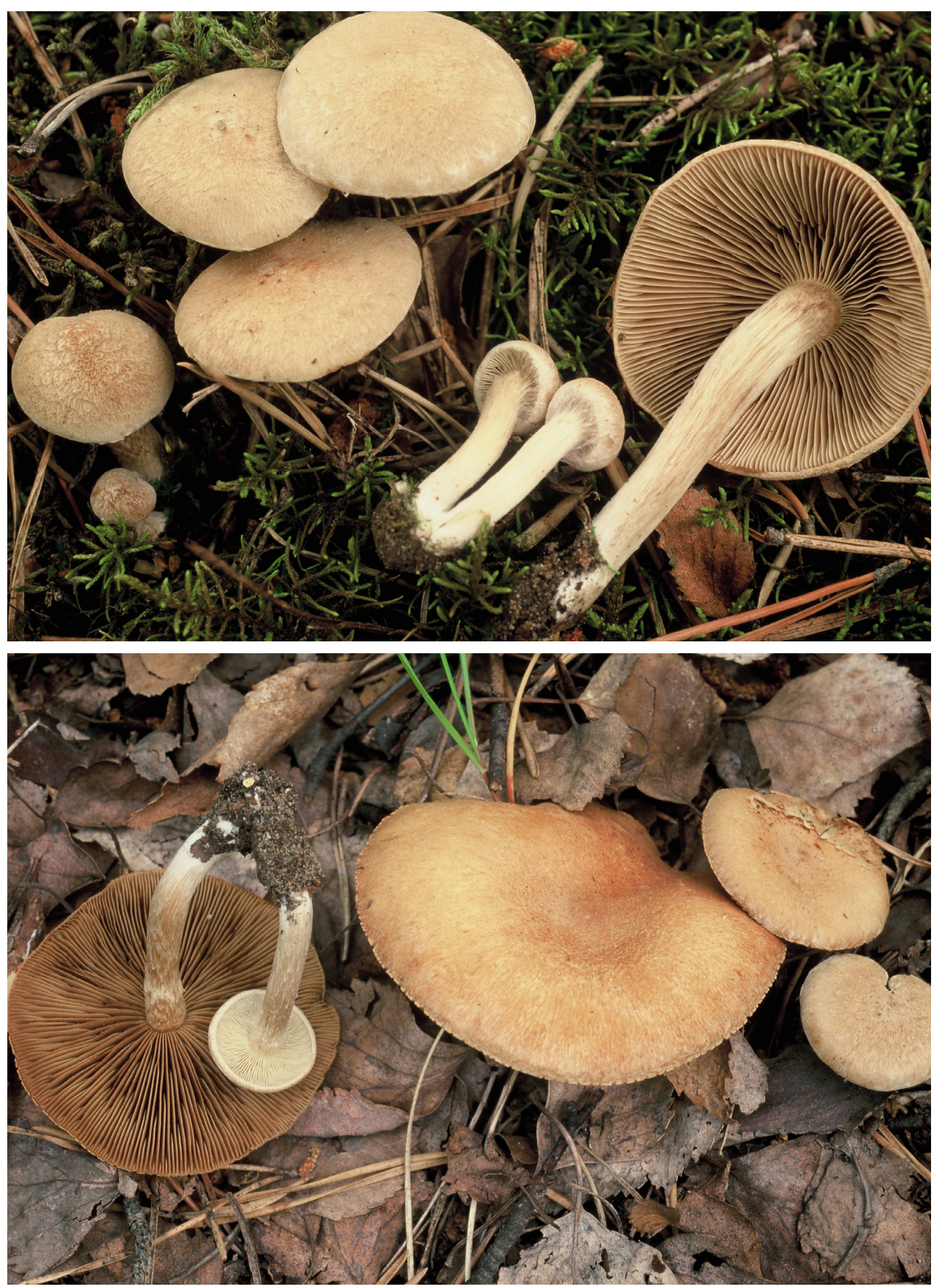

Figs. 1-2. Fruit bodies of Inocybe myriadophylla in situ (holotype). - Photo: J. Vauras 

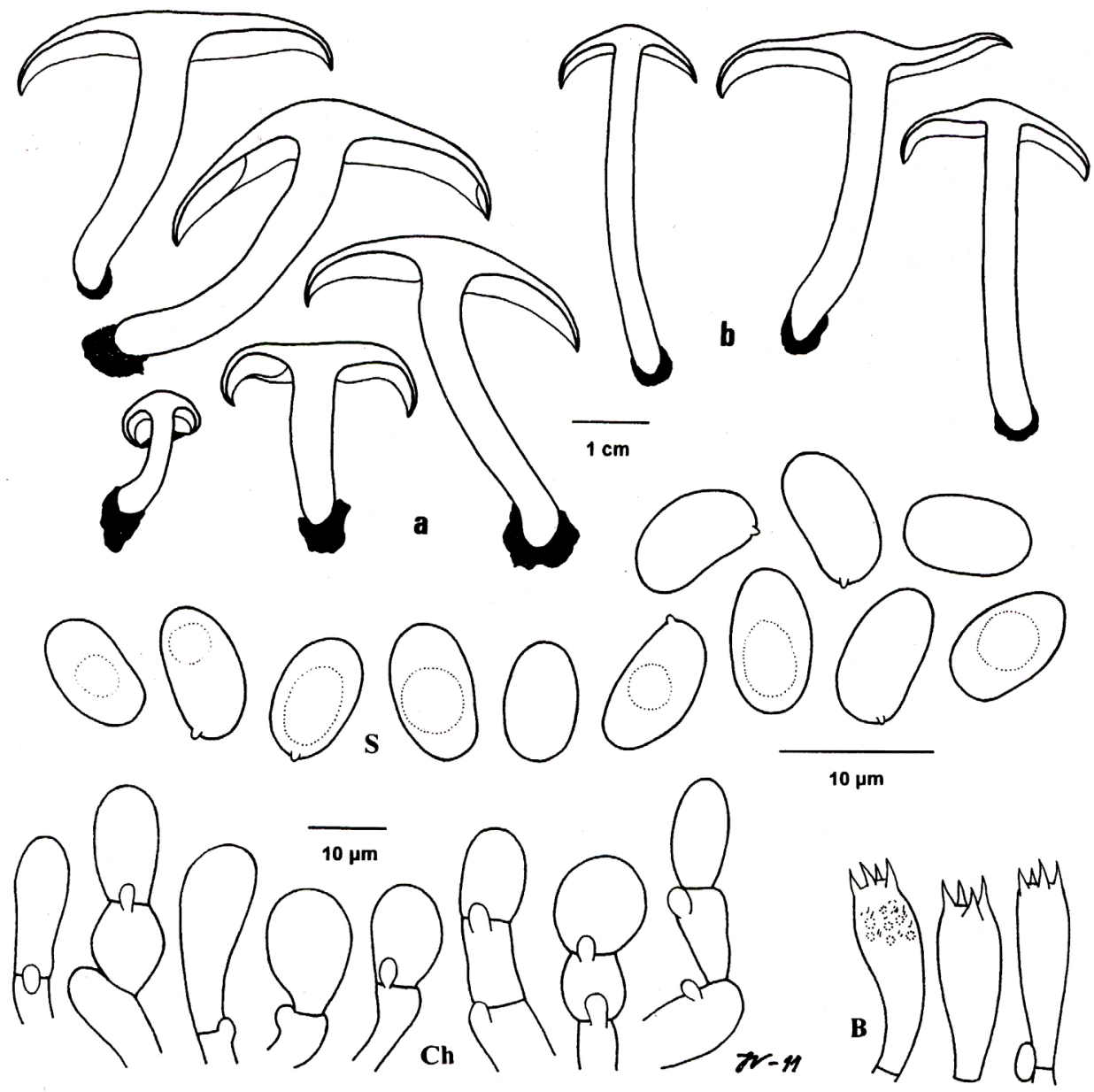

Fig 3. Inocybe myriadophylla . Cross-sections of fruit bodies ( $=$ Vauras 27707F, $\mathrm{b}=$ Vauras 28132) and microscopical characters (holotype), $\mathrm{B}=$ basidia, $\mathrm{Ch}=$ cheilocystidia, $\mathrm{S}=$ spores.

6-14 um, clavatis, pyriformibus vel subglobosis. Saltem cum Betulis. Ex speciebus aliis borealibus subgenus Mallocybe lamellis densis differt.

Typus: Finland. Varsinais-Suomi. Lohja, Virkkala, Kyrkstad, ca $450 \mathrm{~m} \mathrm{NNW}$ of the church, E side of the road Tynninharjuntie, on bank, forest margin with Pinus sylvestris, Picea abies, Salix caprea, Betula pendula and Populus tremula, Grid $27^{\circ} \mathrm{E}$ : 66788:33334, alt. ca 60 m, 1.VII.2003 Vauras 19678F (TUR-A 149646 - holotypus, GenBank no. HM209793; GB, H, WTU - isotypi).
Etymology: myriadophylla refers to the crowded lamellae of the species.

Pileus 1.8-5.3(-7.5) cm diam, when young hemispherical with inflexed margin, then planoconvex with inflexed to deflexed margin, centre sometimes obtusely umbonate; when young pale brownish grey $(71 \mathrm{M})$ to yellow-brownish grey, then grey-brown (70M), pale brown (S20Y50M20) to brown, centre often darkest, yellow-brown; tomentose, at margin sometimes with pieces of whitish tissue. Lamellae narrow, up to $4 \mathrm{~mm}$, rarely to $7 \mathrm{~mm}$ broad, crowded, adnate to subdecurrent, when young pale grey, 


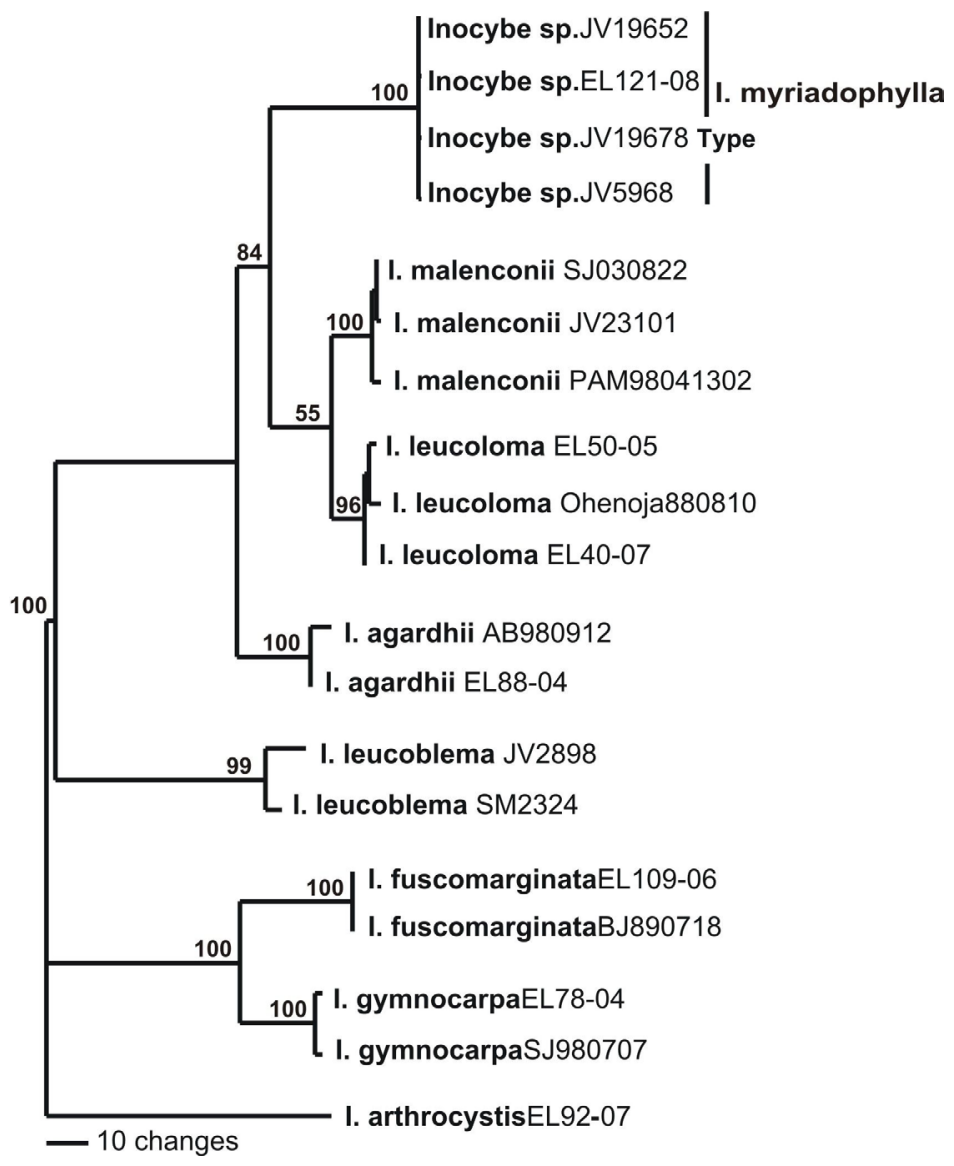

Fig. 4. One of the most parsimonious trees obtained from the parsimony analysis showing the position of the new species I. myriadophylla. Bootstrap values are indicated on branches.

then brownish grey, later grey-brown, brown to fairly dark brown, edge pale, even. Stipe $2.5-5$ x $0.3-0.7 \mathrm{~cm}$, cylindrical or slightly tapering towards base, whitish to pale grey, then pale brown to pale grey-brown, base white; fibrillose, silky shiny, solid, later often hollow; often 2-4 fruit bodies growing cespitose. Cortina pale grey, fairly abundant. Context pale greyish yellow to yellow-brown, shiny. Odour indistinct to somewhat fungoid and slightly metallic. Taste mild, but slowly somewhat unpleasant. Spores (7.3-) 7.9-9.6(-10.6) × (4.5-)4.7-5.5(-5.7) $\mu \mathrm{m}$, mean $8.8 \times 5.1 \mu \mathrm{m}$, range of mean values $8.7-9.1 \times$ 4.9-5.2 $\mu \mathrm{m}, \mathrm{Q}=(1.5-) 1.6-1.95(-2.0)$, mean $\mathrm{Q}=$ 1.74 , range of mean $\mathrm{Q}$-values 1.73-1.76; smooth, regular to phaseoliform. Basidia 20-34 × 7-9 $\mu \mathrm{m}(\mathrm{n}=40)$, mean $28 \times 8 \mu \mathrm{m}$ cla- vate, 4-spored. Cheilocystidia 9-30 × 6-14 $\mu \mathrm{m}$ $(\mathrm{n}=41)$, mean $20 \times 10 \mu \mathrm{m}$, clavate, pyriform or subglobose, some with greyish to brownish yellow contents. Pleurocystidia absent. Caulocystidia occurring at the apex of the stipe, similar to cheilocystidia, but on average larger, up to 40 $\mu \mathrm{m}$ long and $20 \mu \mathrm{m}$ wide.

\section{Ecology, distribution and phenology}

Inocybe myriadophylla seems to be a mycorrhizal species of Betula in habitats on calcareous soil. Betula was present at every site, where this fungus was found. The localities are fairly open, parks or forest margins, or fairly young mixed forests with adult Pinus sylvestris. Fur- 
thermore, in one locality the only tree species was Betula. Most of the localities are close to limestone processing plants, and have received fallout of chalk dust for years. The soil $\mathrm{pH}$ of the localities in Lohja and Parainen ranged between 7.4 and 7.8 .

At present, we know only a few localities of I. myriadophylla from Finland and Sweden. All these are situated in hemiboreal (or boreonemoral) zone. In both localities, where the species has been collected several times, it grows as abundant groups. I. myriadophylla seems to have a fairly long fruiting period, as the collections date from mid-June to mid-September.

Specimens studied: FINLAND. Varsinais-Suomi. Lohja, Tytyri, 14.VIII.1989 Vauras 3572* (TUR-A); Virkkala, Kyrkstad, 1.VII.2003 Vauras 19678F* (TURA, holotype), 1.IX.2010 Vauras 27707F (TUR-A, MCVE), 27708* (TUR-A), 11.IX.2010 Vauras 27787F (TUR-A). Parainen, town, Malmnäs, 30.VIII.1991 Vauras $5968 F^{*}$ (TUR-A, GB, H, TU, WTU), 2.IX.1992 Vauras 7109 (TUR-A), 17.VI.2003 Vauras $19652 F$ (TUR-A), 30.VIII.2009 Vauras 28132* (TUR-A, G, MICH, OULU, PC, UPS). SWEDEN. Närke. Axberg, Kvinnerstatorp, 10.IX.2008 Larsson 121-08*(GB).

\section{Results and discussion}

The aligned dataset comprised 19 collections and had 2192 characters. After exclusion of ambiguous regions 1801 characters remained for the analysis. Of these 1554 were constant, 67 were variable and parsimony uninformative, and 180 were parsimony informative. The maximum parsimony analysis yielded 13 equally most parsimonious trees (length $=323, \mathrm{CI}=0.8731$, $\mathrm{RI}=0.9168$ ), one of which is presented in Fig 4. Bootstrap values are indicated above branches.

Bootstrap analysis recovered seven clades corresponding to the species: Inocybe gymnocarpa Kühner (100\%), I. fuscomarginata Kühner $(100 \%)$, I. agardhii (N. Lund) P.D. Orton (100\%), I. leucoblema Kühner (99\%), I. leucoloma Kühner (96\%), I. malenconii R. Heim $(100 \%)$ and Inocybe sp. (= I. myriadophylla; $100 \%)$. The results show that the specimens from the morphologically identified new species form a strongly supported clade, which is closely related to I. malenconii and I. leucoloma (Fig. 4).

Inocybe myriadophylla differs easily from I. malenconii, which has longer spores $(9-12 \times$ 4-5.5 $\mu \mathrm{m})$ with mean $\mathrm{Q}$-value of ca 1.95. The latter species is also smaller, more brown, and has a finely scaly pileus. I. leucoloma grows in alpine and arctic habitats above the treeline. $I$. agardhii has somewhat larger fruit bodies, as well as larger spores, and grows with Salix.

Acknowledgements: Grants (to EL) from the Swedish Taxonomy Initiative, ArtDatabanken, SLU Uppsala and Kapten Carl Stenholm's foundation are gratefully acknowledged. Ernest Emmett is warmly thanked for improving the English.

\section{References}

Cailleux, A. 1981: Code des couleurs des sols. - Boubée. Cripps, C.L., Larsson, E. \& Horak, E. 2010: Subgenus Mallocybe (Inocybe) in the Rocky Mountain alpine zone with molecular reference to European arcticalpine material. - North American Fungi 5: 97-126.

Jacobsson, S. 2008: Inocybe (Fr.) Fr. - In: Knudsen, H. \& Vesterholt, J. (eds.). Funga Nordica. Agaricoid, boletoid and cyphelloid genera: 868-906. Copenhagen.

Katoh, K., Kuma, K., Toh, H. \& Miyata, T. 2005: MAFFT version 5: Improvement in accuracy of multiple sequence alignment. - Nucleic Acids Research 33: 511-518.

Kühner, R. 1988: Diagnoses de quelques nouveaux Inocybes récoltés en zone alpine de la Vanoise (Alpes françaises). - Documents Mycologiques 19 (no.74): $1-27$.

Küppers, H. 1981: DuMont's Farben-Atlas. $2^{\text {th }}$ ed. -163 pp. DuMont Buchverlag, Köln.

Larsson, E. \& Örstadius L. 2008: Fourteen coprophilous species of Psathyrella identified in the Nordic countries using morphology and nuclear rDNA sequence data. - Mycological Research 112: 1165-1185.

Ryberg, M., Larsson, E. \& Jacobsson S. 2010: An evolutionary perspective on morphology and ecological characters in the mushroom family Inocybaceae (Agaricomycotina, Fungi). - Molecular Phylogenetics and Evolution 55: 431-442.

Swofford, D.L. 2003: PAUP*. Phylogenetic Analysis Using Parsimony (* and Other Methods). Version 4. Sinauer Associates, Sunderland, MA. 